\title{
Research on the Development Trend of Decathlon Athletics Performance in Liaoning Province Since the Founding of New China and Its Countermeasures
}

\author{
Peng Fu \\ Vocational and Technical College \\ Anshan Normal University \\ Anshan, China 114016
}

\begin{abstract}
Known as "the king of the track and field", allround competition consists of running, jumping and casting, with various events, complex technology and high requirements for physical and psychological quality. In recent years, the all-round competition lags far behind the world-class advanced level. Athletes in all-round event in the track and field team of Liaoning province are researched. Literature review method, expert interview method and logic induction method and comparative analysis method are used to comprehensively research the current situation of all-round competition in Liaoning province, analyze characteristics of it and research the development trend, and then propose countermeasures applicable to its development.
\end{abstract}

Keywords-Liaoning province; performance; men's and women's all-round events; development

\section{INTRODUCTION}

The level of all-round competition is an important indicator to evaluate the level of men's track and field. The decathlon in modern world has developed to pretty high level, from 6,087 points in 1922 to 9,026 points in 2001, up 2,939 points. At the beginning of the 1990 s, the national record of men's decathlon reached 7,908 points. During 1991 and 2000 , the point of decathlon in our country is around 7,800 with slow development and lagging far behind the world standard. For example, in 2002, Qi Haifeng, the athlete ranking first in our country gained 8,041 points, ranking the 20 th in the men's decathlon in the world $(8,126$ points in 2003). Although it is a long-term objective for decathletes in our country to catch up with and surpass the world's advanced level, it is promising to rule the roost in Asia and enter the world's top ranks through referring to successful experience of foreign countries in training excellent decathletes, analyzing the reasons of backward decathlon in our country and improving it.

All-round competition is the comprehensive events consisting of running, jumping and casting. Theoretically, sub-events in it should develop evenly. Although people propose all-round competition needs all-round development, in practice, the results of sub-events are unbalanced and it is universal. Sub-events in all-round competition have different characteristics and specific requirements for athletes. The requirements of different sub-events are contradictory in some aspects. Besides, athletes have different characteristics. Therefore, it is difficult and impractical to develop subevents evenly. Comprehensive or balanced development refers to personal ability of athletes. There is no absolute comprehensive or balanced development.

\section{RESEARCH OBJECTS AND METHODS}

\section{A. Research Object}

Liaoning decathletes who gain sports results and ranking of the national or above the national level are chosen as the research objects.

\section{B. Research Methods}

1) Literature review method: According to the research needs, literatures related to current situation of track and field, all-round events and reserve talents for competitive sports are collected through Wanfang database, library of Liaoning Normal University, Chinese Academic Periodical Net and CNKI, in order to understand the current situation of researches on all-round competition at home and abroad, and systematically research, analyze and conclude. The dynamic condition related to track and field at home and abroad and physical truth of reserve talents in high-level sports team are searched through China Sports Online, Official Website of Chinese Athletic Association and other related websites to make the research practical.

2) Comparative analysis method: According to the development status of jumping event of Liaoning province, compare results achieved in different years to find the problems in it and the advantages in future development.

3) Expert interview method: In order to understand the development status of jumping event of Liaoning province more deeply, interview influential professors in track and field as well as senior coaches in jumping event and seek advice from experts to lay solid foundation for deeper exploration and research on the development of jumping event of Liaoning province. 
4) Logic induction method: According to the materials collected, conclude, sort, reason and demonstrate opinions, conclusions and suggestions through principles of logic.

\section{RESULTS AND ANALYSIS}

\section{A. Development Status of Men'S Decathlon in Liaoning Province Since the Founding of New China}

According to the even-group theory of educational expert in track and field of our country, sport events can be divided into dominant event, potential superior event, development pending event on the basis of existing level and development potential. Scholars further define "dominant event" which refers to the sport event that can keep high standard in athletic competition at home and abroad, achieve excellent results and have advantages in future competition. The results of national track and field events of athletes in Liaoning province indicate all-round event has been the dominant event in our province since the beginning of the 1990s. The growth of Qi Haifeng promotes the level of allround events in our province furthest.

\section{B. Current Situation and Analysis on Coach Team of All- Round Event in Liaoning Province}

The current sport results and requirements of scientific training reveal athletes and coaches are participators in core status in athletic training. Furthermore, coaches are direct organizers in training athletes, directly influencing the development of competitive sports. They play a dominant role in guiding sport technique and improving the technical level of athletes.

\section{Main Source of Coach Team in All-Round Events of Liaoning Province}

The investigation shows coaches of jumping event are retired athletes, graduates of PE major and athletes in special event of all-round event. Most coaches of all-round events in Liaoning province are retired athletes, and few come from universities, so they can be defined as front line coaches. Although with rich experience in training and competition, these retired coaches can directly serve as coaches, they lack culture base and theoretical knowledge, having difficulties in guiding the training through knowledge related to human anatomy, exercise physiology and sports biomechanics. Moreover, they fail to understand and accept the national training index and advanced training method. Therefore, in order to improve the level of all-round competition, we should restrict and optimize coaches to make them get continuous development. Coaches employed through other ways have defects in knowledge structure and training ability, which will influence the training and results of athletes. They can be defined as the second line coaches.

\section{Ability Structure of Coach Team}

We can comprehensively analyze and investigate education background, scientific research, training and learning of coaches to solve problems. Education background is one of the standards to measure the ability level of people in knowledge acceptance, referring to the degree of receiving education. Coaches with potential ability in training and scientific research and those having received higher education are qualified if they can apply theoretical knowledge to practice. In sports training, the ability and cultural quality of coaches play decisive roles in continuously improving the training level of sports team.

Coaches have few opportunities to attend training yearly. We should expand the channel of on-the-job training for coaches and improve their knowledge system, accept advanced knowledge theory and scientific and technological level as well as ideas at home and abroad; meanwhile, continuously update and reform new contents of training, expand thinking of scientific training and improve training method, let grass-roots coaches participate in more training and learning, in order to make the training methods more scientific and continuously improve training level.

\section{ANALYSIS ON COUNTERMEASURES FOR ALL-ROUND COMPETITION IN LIAONING PROVINCE}

All-round events play important role in the development of track and field in Liaoning. Qi Haifeng, the excellent allround athlete in the 1990s breaks the national record and gains national champion. As the excellent representative of all-round athletes of our province, he wins honors for our country and province and achieves excellent results in competitions at home and abroad, making great contributions for the track and field cause of our province. If we can sum up experience constantly, adopt more effective measures and exploit the traditional advantages to the full, reasonably develop human resources, gather manpower, material resources and financial resources at the meantime create better training environment and make the training more scientific, the jumping event of our province will reach a higher level and take the lead in Asia even the world and make prominent contributions for our country before long.

\section{A. Strengthen the Construction of Coach Team}

The introduction of outstanding coaches and special talents is important to improve training level and construct the coach team with reasonable structure, high quality and innovative spirit, providing guarantee and support to improve professional skills of coaches and construct high level track and field team with high ideological quality. We can send coaches abroad to learn and exchange, refer to advanced experience in foreign countries and introduce high level foreign coaches, learning from others' strong points to offset our weakness to make the decathlon of our country develop rapidly. Besides, we can establish professional files of coaches.

\section{B. Realize Scientific and Technological Progress and Technical Innovation for Sports}

Competitive sports struggle for sports training and prepare for Olympic Games and the Asian Games. Scientific training methods and scientific research as well as science and technology service are integrated to make the sport skill training more scientific. In the socialist sports cause of our 
country, the science and technology work of sports is vital to promote the development of sports cause and industry. Scientific research integrates with science and technology service to pursue practical results and further improve the athletes' level in sport technique and competitive strength.

\section{Keep Coordinated Development between Mass Track and Field Sports and Competitive Track and Field Sports}

Mass sports and competitive sports are mutually connected, dialectical and unified. For mass sports, competitive sports can arouse interests, have demonstration effect and provide conditions. For competitive sports, mass sports can lay foundation, inspire the fighting spirit, find talents and embody values. At present, we should attract more people to participate in track and field and spread correct skills as well as vigorously develop track and field sports. Meanwhile, we can make it popular, gain people's favor and find and cultivate excellent players timely. The basic skill training and physical exercise proceed at the same time. Therefore, we should keep coordinated development and common progress of mass track and field sports and competitive track and field sports.

\section{Strengthen Selection and Training of Reserve Talents of All-Round Events}

Decreasing number of talents in track and field of our country attend athletic training, which indicate reserve talents of track and field sports are on the decrease. Without sufficient reserve talents, it becomes empty talk that the track and field events enter world advanced level and the competitiveness of track field will become worse and worse. Without long-rang planning, we cannot develop and construct talent training system. In order to improve the integral level of a sport event, we must pay attention to talent selection of it. Besides, previous pattern that supplies athletes has failed to adapt to social development. Therefore, we must furthest improve the quality and efficiency of athletic training for adolescents in order to achieve better results and realize long-term development of jumping event.

\section{E. Improve Training and Selection of Sports Talents in Universities}

Numerous excellent athletes in foreign countries are trained in universities. We should make the best of universities to train sports talents. General Administration of Sport of China and China's Higher Education Committee can jointly organize events, select excellent sports talents, train and manage them in universities as well as increase investment to promote the development of universities and athletes.

Many factors influence the development of all-round competition in Liaoning province. The results of all-round events fluctuate and tend to improve continuously. Favorable factors promote its development while negative factors impede it. We should exploit the advantages of Liaoning province to the full and timely improve or eliminate adverse factors to promote the rapid and sustainable development of all-round competition in Liaoning province.

\section{CONCLUSION}

1. The results of men's decathlon in Liaoning province have downtrend in recent years. With the decline in Qi Haifeng's performance, the all-round competition in our province even the whole country is under the influence. Therefore, we should start with children and pay attention to the construction of young team and the trapezoidal progress of it.

2. Women's decathlon in Liaoning province fail to receive due attention. The best result appeared in 2000. It ranked the second and the third in the 1990s. Women's decathlon of our province had its advantages after Du Xueru won a championship on the national track and field championship meet in 2000. Mei Yiduo took the crown on the national track and field championship in 2011.

3. The all-round sports in Liaoning province have simple financial resources and low level in sports team management and lack sponsorship from large-scale enterprises and individuals. It has poor popularity because of insufficient publicity. Furthermore, it neither cooperates with universities in the province nor makes the best of advantages of them in scientific research and human resources.

4. Development countermeasures for all-round event of Liaoning province: strengthen the construction of coach team; promote scientific and technological progress and technical innovation of sports; keep coordinated development of mass track and field and competitive track and field; strengthen the selection and training of reserve talents of all-round events; make the decision-making and management of sports more scientific; intensify investment and absorb funds in multiple channels.

5. Select talents scientifically: special objectives should be provided for special age grades. We should select and train talents early to avoid defects caused through missing the optimum opportunity. Meanwhile, attentions should be paid to psychological indexes in talent selection.

6. Systematic training: set long-term objectives of decathlon training, strengthen the coordinated development of key training and training of single event as well as connection training, pay attention to the training for psychological quality of decathletes.

\section{REFERENCES}

[1] Xue Jiying. Analysis on Scoring Table for All-round Events of International Association of Athletics Federations [M], Journal of Beijing Sport University, 1994, (3)-17

[2] General Administration of Sport of China, Textbook for On-the-job Training of Chinese Coaches-Track and Field [M], Beijing: People's Sports Publishing House, 1999(1)

[3] Yuan Zuosheng, Nan Zhongxi. Scientific Training Methods for Modern Track and Field Athletics [M], Beijing: People's Sports Publishing House, 1997 
[4] Liu Min. Current Situation and Countermeasures of All-round Events in Guangxi $[\mathrm{J}]$, Journal of Guangxi University for Nationalities, 2001(2) 154-156

[5] Yuan Zunhui. Analysis on the Fujian Track and Field Team in the 11th National Athletic Meet [J], Fujian Sports Science and Technology, 2009(6) 13-19

[6] Chen Tao. Analysis on the Development Direction of Track and Field Athletics in Our Country through the Track and Field Athletics in the 11th National Athletic Meet [J], Journal of Capital Institute of Physical Education, 2007(1) 88-90

[7] Yang Cunbin. Multi-analysis on Men's Decathlon [M], Track and Field Guide, 1992, (2)-11

[8] Cao Xiaowen. 1500M in Decathlon of Our Country Urgently Needs Improvement [M], Journal of Xi'an Institute of Physical Education, 1994, (3)-71-7

[9] Wen Chao. High-grade Tutorial of Track and Field [M], Beijing: People's Sports Publishing House, 1994

[10] Wen Chao. Discussion on Hotspots of Track and Field [M], Beijing: People's Sports Publishing House, 1995

[11] Yuan Zuosheng. Scientific Training Method Methods for Modern Track and Field Athletics [M], People's Sports Publishing House, 1997

[12] Sports Statistics Yearbook (From 2000 to 2004) [C], Compiled by Department of Policies and Laws of General Administration of Sport of China. 